\title{
p53 and VEGF expression are independent predictors of tumour recurrence and survival following curative resection of gastric
}

\section{cancer}

\author{
C Fondevila', JP Metges², J Fuster', JJ Grau ${ }^{3}$, A Palacín ${ }^{4}$, A Castells ${ }^{5}$, A Volant ${ }^{2}$ and M Pera*,1,6 \\ 'Senvices of Gastrointestinal Surgery, Institut de Malalties Digestives, Hospital Clínic, Institut d'Investigació Biomèdica August Pi i Sunyer (IDIBAPS), \\ University of Barcelona Medical School, Barcelona, Spain; ${ }^{2}$ Departments of Pathology and Medical Oncology, Centre Hospitalier Universitaire Cavale \\ Blanche and Morvan, Brest, France; ${ }^{3}$ Department of Medical Oncology, Hospital Clínic, IDIBAPS, University of Barcelona Medical School, Barcelona, Spain; \\ ${ }^{4}$ Department of Pathology, Hospital Clínic, IDIBAPS, University of Barcelona Medical School, Barcelona, Spain; ${ }^{5}$ Services of Gastroenterology, Institut de \\ Malalties Digestives, Hospital Clínic, Institut d'Investigació Biomèdica August Pi i Sunyer (IDIBAPS), University of Barcelona Medical School, Barcelona, \\ Spain
}

This study was undertaken to determine the value of tumour microvessel density (MVD) and the expression of p53 and vascular endothelial growth factor (VEGF) as prognostic markers in patients with gastric cancer operated on for cure. In all, I 56 patients with curatively resected gastric cancer constituted the basis of this blinded retrospective evaluation. Patients were treated with either surgery alone $(n=53)$ or surgery plus adjuvant chemotherapy $(n=103)$. Tumour MVD, p53 expression, and VEGF expression were assayed using immunohistochemical techniques. After a mean follow-up of 43 months, 64 (4I\%) patients had died and 55 (35\%) patients developed tumour recurrence. Positive correlations between MVD and both p53 $(P=0.005)$ and VEGF $(P=0.005)$ expression were observed. Both MVD $\geqslant 100(P=0.05)$ and positive VEGF expression $(P<0.02)$ were associated with shorter disease-free survival, and positive VEGF expression $(P=0.0 \mathrm{I})$ was also associated with shorter overall survival. Multivariate analysis confirmed that, in addition to the pathological tumour stage, lymph node ratio, the extent of lymphadenectomy and perineural invasion, p53 expression, and VEGF expression were independently associated with both disease-free survival $(P<0.0005$ and 0.02 , respectively) and overall survival $(P<0.02$ and 0.01 , respectively). Finally, patients whose tumours did not show p53 expression had a survival benefit compared to those expressing p53 when treated with adjuvant chemotherapy $(P=0.0 \mathrm{I})$. This investigation demonstrates that p53 expression and VEGF expression are independent prognostic factors for both disease-free survival and overall survival in patients with curatively resected gastric cancer, and that p53 status may also influence response to chemotherapy. British Journal of Cancer (2004) 90, 206-215. doi:I0.1038/sj.bjc.660I455 www.bjcancer.com (C) 2004 Cancer Research UK

Keywords: angiogenesis; gastric cancer; p53; VEGF; prognostic factors; microvessel density

Until the 1980s, gastric cancer was one of the most frequent tumours in the world and the leading cause of cancer death (Parkin et al, 1999). In recent decades, the incidence has declined, but the prognosis of gastric cancer in the Western countries has not improved, the 5-year survival being 20-30\% (Hundahl et al, 2000; Greenlee et al, 2001). Surgical resection is the most powerful tool to improve prognosis, whereas the major problem is delayed diagnosis resulting in advanced disease. In most American and European series, almost $60 \%$ of operated patients have pathological tumour (pT) stages 3 and 4 . Screening programmes are not usually performed due to their high cost and minimal benefit in decreasing mortality rates (Lacueva and Calpena, 2001).

In curatively resected patients, the biologic nature of the tumour determines survival since almost half will die from recurrent

Correspondence: Dr M Pera; E-mail: mpera@clinic.ub.es

${ }^{6} \mathrm{M}$ Pera's current address: Service of Gastrointestinal Surgery, Institut de Malalties Digestives. Hospital Clínic. Villarroel 170, 08036 Barcelona, Spain.

Received 2 July 2003; revised 25 September 2003; accepted 6 October 2003 cancer (Averbach and Jacquet, 1996). The poor prognosis of patients with recurrent disease is due to the lack of an effective rescue treatment. In fact, the number of patients with recurrent gastric cancer in which it is feasible to perform curative surgery is less than $4 \%$ (Yoo et al, 2000). It seems necessary to evaluate new biological markers that may predict the natural history of the disease as a guide to treatment. Newer tumour markers include tumour suppressor gene p53, vascular endothelial growth factors (VEGFs), and microvessel density (MVD) as a measure of new blood vessel growth or angiogenesis. Without blood vessels, tumours cannot grow beyond a critical mass nor create metastases (Castells and Rustgi, 2003). A hypoxic environment and genetic instability in the centre of the tumour allows the evolution of cellular clones with the loss of p53 function. These cells have a lower apoptotic rate and produce angiogenic factors like VEGF, inducing new vasculature (Harris, 1997). These factors might provide information to help predict the prognosis of patients with gastric cancer. However, the prognostic value of p53 expression in these patients is controversial (Gabbert et al, 1995), although it has been related to the development of higher MVD (Maehara et al, $2000 \mathrm{~b}$ ). The expression of VEGF has been associated with vascular 
invasion, liver metastases (Takahashi et al, 1996), and lymph node metastases (Maeda et al, 1996). Inhibition of the VEGF pathway using monoclonal antibodies has shown potent antitumour effects in animal models (Witte et al, 1998), and this might be a new approach to treat these patients in the future.

The use of adjuvant chemotherapy in gastric cancer is still controversial and has been reviewed in several meta-analyses (Hermans et al, 1993; Earle and Maroun, 1999). One review concluded that adjuvant chemotherapy produced marginal benefit in the survival of curatively resected patients (Earle and Maroun, 1999), but it is clearly necessary to find more effective treatments. Differing responses to chemotherapy may be due to biological characteristics of the tumour such as p53 status, since p53dependent apoptosis modulates the cytotoxic effects of antitumour agents such as 5-fluorouracil, doxorubicin, and cisplatin (Chin et al, 1992; Lowe et al, 1993), commonly used as adjuvant therapy. Knowing the p53 status of the individual patient might allow us to select those cases most likely to respond to adjuvant therapy.

The aim of this study was (1) to investigate whether MVD as well as p53 expression and VEGF expression are independent prognostic factors for patients with gastric cancer undergoing curative gastrectomy, and (2) to evaluate their predictive value for clinical outcome following adjuvant chemotherapy.

\section{PATIENTS AND METHODS}

A consecutive series of 206 patients with primary gastric cancer received surgical treatment at our hospital between January 1989 and October 1998 . The mean age was $67 \pm 12$ years (range: $23-93$ years), and $130(63 \%)$ patients were male. Of them, $164(80 \%)$ patients underwent potentially curative resection (R0 resection following UICC criteria $^{18}$ ), defined as macroscopically and microscopically complete removal of the tumour on intraoperative and histopathologic evaluation. Eight patients (5\%) died within 60 days after surgical treatment and were excluded from this analysis. Accordingly, 156 patients constituted the basis of the study.

The characteristics of patients included in the study are shown in Table 1. Staging and grading were referred to the fifth edition of the tumour-node metastasis (TNM) classification of the International Union Against Cancer (UICC) (Sobin and Fleming, 1997). Accordingly, 19 patients (12\%) were classified as UICC stage IA, 39 $(25 \%)$ as stage IB, $42(27 \%)$ as stage II, $27(17 \%)$ as stage IIIA, 21 $(13 \%)$ as stage IIIB, and eight $(5 \%)$ as stage IV.

The surgical technique in this group was as follows: 76 subtotal gastrectomies (49\%), 77 total gastrectomies (49\%), and three stump gastrectomies (2\%). Based on the decision of the surgeon, $50(32 \%)$ patients had a D1 lymphadenectomy, including the firstlevel lymph nodes (paracardial, major and minor curvature, supra-, and infrapyloric) and $106(68 \%)$ patients had a D2 lymphadenectomy, in which the second-level nodes (left gastric artery, hepatic artery, celiac trunk, splenic hilum, and splenic artery) were also excised. Splenectomy to ensure complete resection of the tumour was performed in 49 patients (31\%). A perioperative histological frozen section of the resection margin was always performed to rule out tumour invasion.

In all, 103 patients $(66 \%)$ received adjuvant chemotherapy based on either mitomycin C $\left(10-20 \mathrm{mg} / \mathrm{m}^{2}\right.$ i.v. every 6 weeks $)(n=38)$ or mitomycin $\mathrm{C}\left(10-20 \mathrm{mg} / \mathrm{m}^{2}\right.$ i.v. on day 1 every 6 weeks) plus tegafur $\left(500 \mathrm{mg} / \mathrm{m}^{2}\right.$ day ${ }^{1}$ for 36 consecutive days) $(n=65)$. The courses were repeated four times as reported previously (Grau et al, 1998).

\section{Follow-up}

Patients were followed up at 3-month intervals over the first 2 years, and at 6-month intervals thereafter. Medical work-up consisted of history and physical examination, haematology and
Table I Demographic, clinical, and tumor characteristics of patients included in the study $(n=156)$

\begin{tabular}{|c|c|}
\hline $\begin{array}{c}\text { Age (years) } \\
\quad<70 \\
\geqslant 70\end{array}$ & $\begin{array}{l}88(56 \%) \\
68(44 \%)\end{array}$ \\
\hline \multicolumn{2}{|l|}{ Gender } \\
\hline $\begin{array}{l}\text { Male } \\
\text { Female }\end{array}$ & $\begin{array}{r}101(65 \%) \\
55(35 \%)\end{array}$ \\
\hline \multicolumn{2}{|l|}{ Tumour location } \\
\hline Cardiac fundus & || (7\%) \\
\hline Body & $62(40 \%)$ \\
\hline Antrum pylorus & $80(51 \%)$ \\
\hline Diffuse & $3(2 \%)$ \\
\hline \multicolumn{2}{|l|}{ Lauren classification } \\
\hline Intestinal & 97 (62\%) \\
\hline Diffuse & $59(38 \%)$ \\
\hline Tumour size (mm) & $54 \pm 27$ \\
\hline \multicolumn{2}{|l|}{ Degree of differentiation } \\
\hline Well & $6(4 \%)$ \\
\hline Moderate & $73(47 \%)$ \\
\hline Poor & 77 (49\%) \\
\hline $\begin{array}{l}\text { Signet-ring cell-type } \\
\text { tumours }\end{array}$ & 41 (26\%) \\
\hline \multicolumn{2}{|l|}{ pT stage $\mathrm{a}^{\mathrm{a}}$} \\
\hline $\mathrm{TI}$ & $28(18 \%)$ \\
\hline T2 & 75 (48\%) \\
\hline T3 & $51(33 \%)$ \\
\hline T4 & $2(1 \%)$ \\
\hline \multicolumn{2}{|l|}{ pN stage ${ }^{a}$} \\
\hline No & $66(42 \%)$ \\
\hline $\mathrm{NI}$ & $54(35 \%)$ \\
\hline N2 & $33(21 \%)$ \\
\hline N3 & $3(2 \%)$ \\
\hline \multicolumn{2}{|l|}{ Lymph-node ratio ${ }^{\mathrm{b}}$} \\
\hline 0 & $66(42.3 \%)$ \\
\hline$<30 \%$ & $48(30.8 \%)$ \\
\hline$\geqslant 30 \%$ & $42(26.9 \%)$ \\
\hline Lymphatic invasion & $44(28.2 \%)$ \\
\hline Vascular invasion & $17(10.9 \%)$ \\
\hline Perineural invasion & $20(12.8 \%)$ \\
\hline \multicolumn{2}{|l|}{$p M$ stage $^{a}$} \\
\hline $\mathrm{MO}$ & |5| (96.8\%) \\
\hline $\mathrm{MI}$ & $5(3.2 \%)$ \\
\hline \multicolumn{2}{|l|}{ pTNM tumor stage ${ }^{\mathrm{a}}$} \\
\hline IA & $19(12.2 \%)$ \\
\hline IB & $39(25 \%)$ \\
\hline$\|$ & $42(26.9 \%)$ \\
\hline$\| I I A$ & $27(17.3 \%)$ \\
\hline$\| I B$ & $21(13.5 \%)$ \\
\hline IV & $8(5.1 \%)$ \\
\hline
\end{tabular}

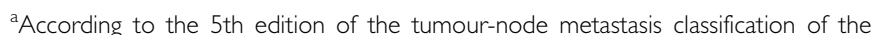
International Union Against Cancer (UICC) ${ }^{18}$. ${ }^{b}$ Number of affected lymph nodes divided by the total number of lymph nodes. PT=pathological tumour; PTNM = pathological tumour node metastasis. $\mathrm{pN}=$ pathological lymph node; $\mathrm{pM}=$ pathological metastasis.

biochemical tests, including serum carcinoembryonic antigen, carbohydrate antigen 19-9, and tissue-associated glycoprotein 72-4 concentration, and chest radiography, abdominal ultrasonography, and endoscopy. If local tumour recurrence and/or metastasis were suspected, the confirmation of the diagnosis by biopsy or a second surgical exploration was attempted. 


\section{Immunohistochemical methods}

Paraffin-embedded tissue blocks of formalin-fixed surgically resected samples were processed for conventional histological study and for immunohistochemical analysis. Immunohistochemical studies were performed using the automated immunohistochemical system TechMate 500 (Dako, Carpinteria, CA, USA), using the EnVision system (Dako). Briefly, $4 \mu \mathrm{m}$-thick sections were deparaffinised and hydrated through graded alcohol and water. Peroxidase was blocked for $7.5 \mathrm{~min}$ in ChemMate peroxidase-blocking solution (Dako). Then the slides were incubated with the primary antibodies for $30 \mathrm{~min}$ and washed in ChemMate buffer solution (Dako). The peroxidase-labelled polymer was then applied for $30 \mathrm{~min}$. After washing in ChemMate buffer solution, the slides were incubated with the diaminobenzidine substrate chromogen solution, washed in water, counterstained with haematoxylin, washed, dehydrated, and mounted. Antigen retrieval was performed in citrate buffer, $\mathrm{pH} 6.0$, in a pressure cooker. The following antibodies were used in this study: monoclonal antibody against p53 (clone BP53-12 at a 1:50 dilution, Novocastra, Newcastle upon Tyne, UK), polyclonal antibody against VEGF (clone A-20 at a 1:300 dilution, Santa Cruz Biotechnology, Santa Cruz, CA, USA), and a monoclonal antibody against the CD34 antigen (clone QBEnd/10 at a 1:200 dilution; Novocastra, Newcastle upon Tyne, UK).

p53 staining analysis Using a light microscope, a visual grading system based on the number of positively stained nuclei of the malignant cells in each tissue was used (Figure 1). If $10 \%$ or more of the malignant nuclei were stained, the slide was scored as positive. If fewer than $10 \%$ of the nuclei were stained, the slide was scored as negative, in accordance with other authors (Kakeji et al, 1993; Maehara et al, 1999). All specimens were analysed by two separate investigators (CF and AV) who were blinded to all clinical information. Conflicts in scores were resolved by consensus.
VEGF staining analysis Vascular endothelial growth factor immunostaining was considered to be positive when unequivocal cytoplasmic staining was seen in the tumour cells, regardless of the number of cells stained. Vascular endothelial growth factor expression was analysed in the invasive front of the tumour away from the tumour centre where necrosis and hypoxia may induce VEGF expression. The intensity of staining for VEGF was graded as follows: - , no detectable expression; + , moderate stain; ++ , strongest stain under a $\times 250$ field (Figure 2). As described by Inoue et al (1997), we used smooth muscle cells as a positive internal control. Two different investigators (CF and AV) assessed the degree of staining without knowledge of the clinical data.

Microvessel staining and counting Quantitative vessel counts were performed by the method described by Weidner and assessed by international consensus (Vermeulen et al, 1996). The entire tumour sections were systematically scanned at $\times 40$ magnification to find the areas of most intense neovascularisation or hot spots. These were identified as having the highest density of brown staining, CD34-positive cells, or cell clusters. For each slide, the most vascular areas within the tumour mass were chosen (Figure 3). A $\times 250$ field in these areas was counted, and the average counts of the fields were recorded. If multiple vascular hot spots were present, counts were performed in each hot spot. Microvessels were defined as a discrete CD34-positive endothelial cell aggregate, with or without definable lumina. The microvessels were counted by two investigators ( $\mathrm{CF}$ and $\mathrm{AV}$ ) who had no knowledge of the other prognostic factors and/or clinical outcomes.

\section{Statistical methods}

The relationship between tumour MVD, p53 expression, and VEGF expression, as well as their correlation with clinicopathological parameters were evaluated by the $\chi^{2}$ test. The length of follow-up

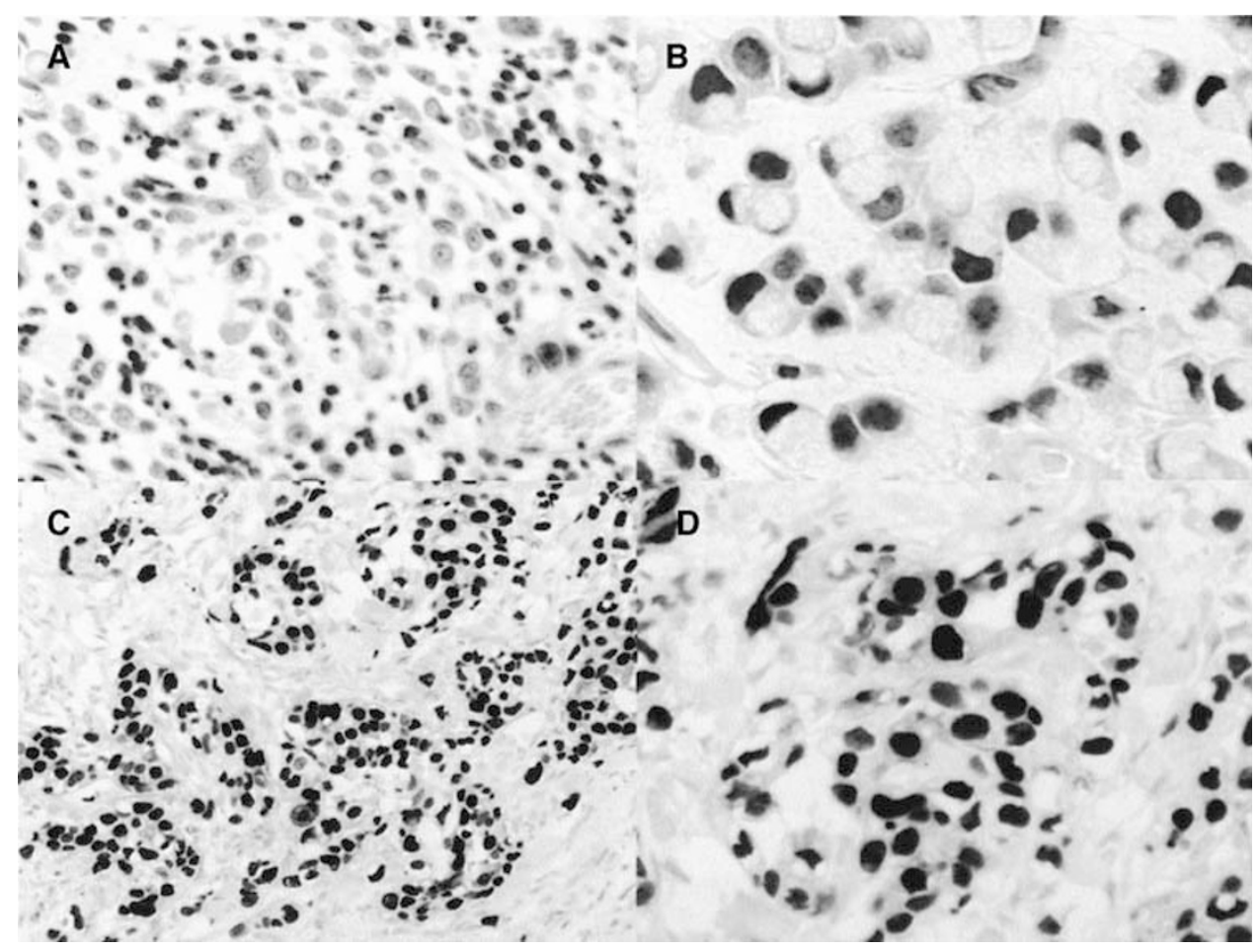

Figure I Diffuse-type gastric cancer with signet ring nucleus. (A and $\mathbf{B})$ No expression of p53. (C and $\mathbf{D})$ Intense staining in the irregular nucleus of tumour cells. 


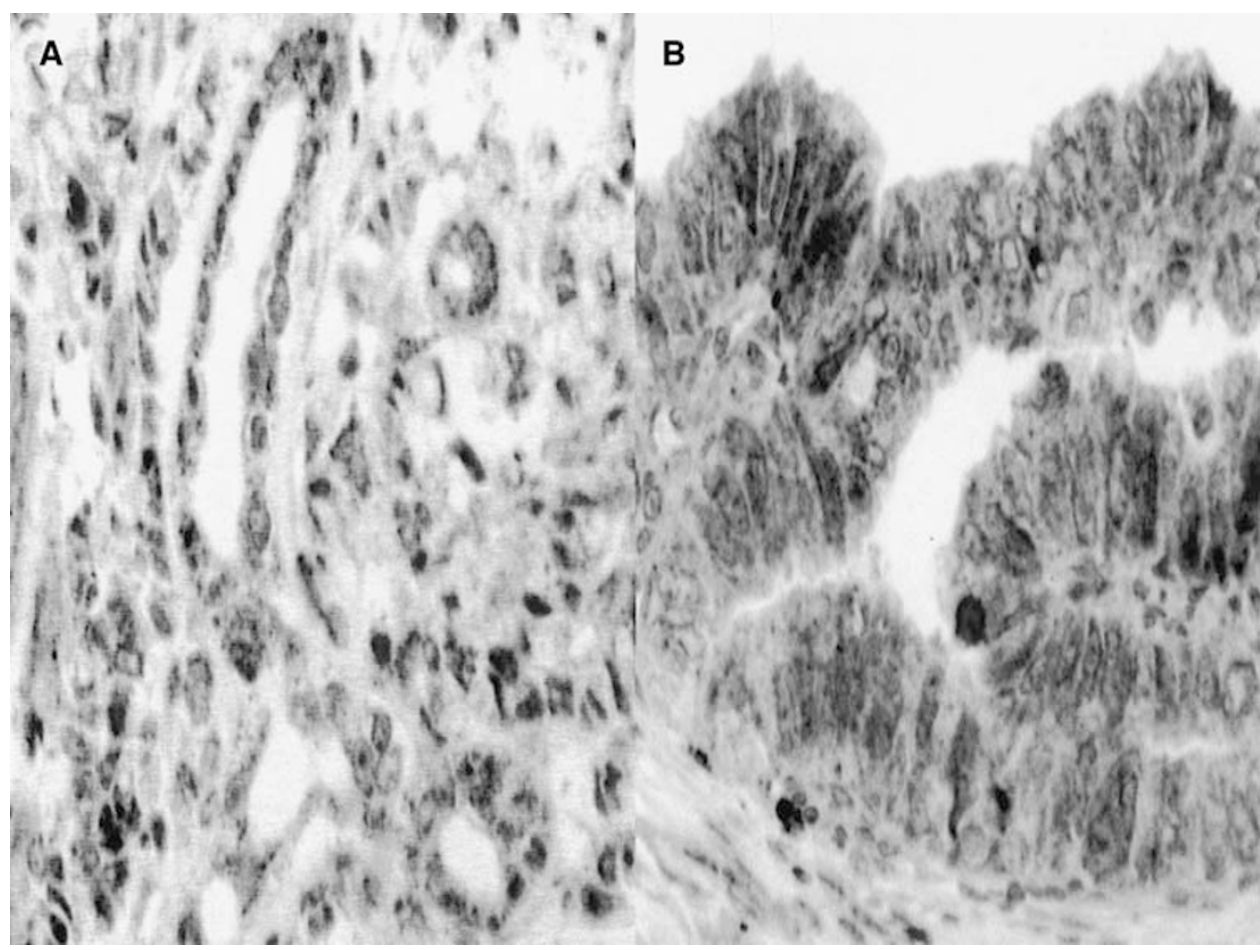

Figure 2 Two samples of gastric tumours with expression of VEGF: $\mathbf{A}(+), \mathbf{B}(++)$. The VEGF appears in the cytoplasm of cells. In $(\mathbf{B})$ the intensity is higher than in $(\mathbf{A})$. The evaluation was carried out in the tumour margins far from the tumour centre where the hypoxia can induce VEGF expression.

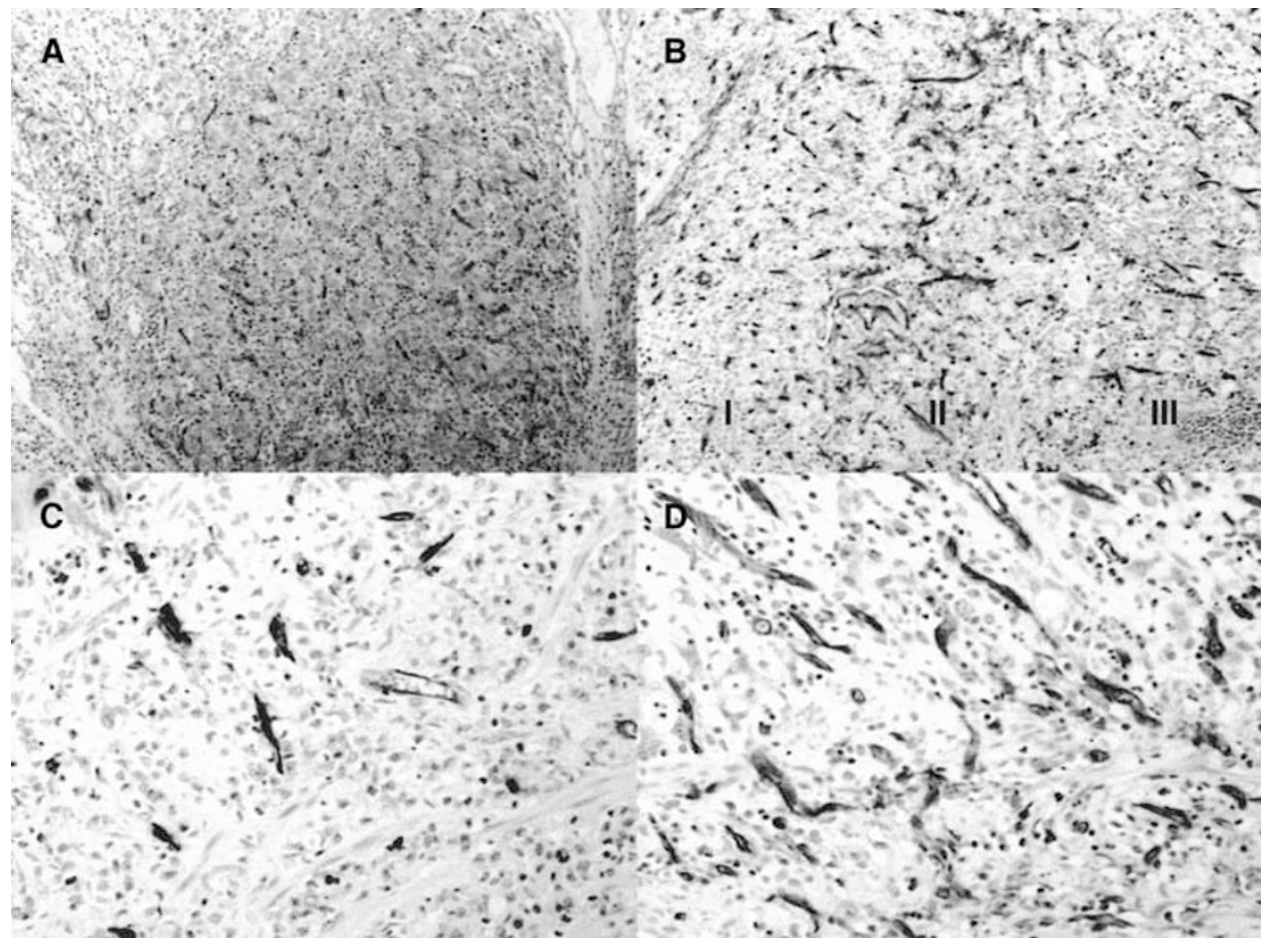

Figure 3 Evaluation of tumour angiogenesis. Identification of external border of tumour growth at $\times 40(\mathbf{A})$ and $\times 100(\mathbf{B})$ magnification field: I (desmoplastic stroma), II (infiltration zone), and III (tumour). At $\times 250$ magnification field (C and $\mathbf{D})$, it is possible to appreciate the differences in the degree of MVD between tumours.

was described as the mean, $95 \%$ confidence interval $(95 \% \mathrm{CI})$, and range. The impact of single parameters on prognosis (tumour recurrence, disease-free survival, and overall survival) was determined by both univariate and multivariate approaches.
Tumour recurrence was evaluated by means of logistic regression analysis. Probabilities of disease-free survival and overall survival were calculated according to the Kaplan-Meier method and compared with the log-rank test. Variables achieving a significance 
level of $P \leqslant 0.1$ in the univariate analysis were subsequently introduced in a forward stepwise proportional-hazard analysis (Cox's model) to identify those variables independently associated with survival. Disease-free survival was established from the time of surgery to the date when recurrence or death was detected. Overall survival was established from the date of surgery to death from any cause or the date of the last follow-up visit. In both cases, patients who were event free at the end of follow-up were censored at that time. For continuous variables (i.e. MVD and lymph node ratio), the cut-off level chosen was their median value. Vascular endothelial growth factor categories were reclassified as negative and positive (including moderate and strong staining) for statistical purposes. Variables actually reflecting a combination of independent parameters (i.e. TNM stage) were not included in the multivariate analysis as a single covariable, but rather decomposed in the corresponding original counterparts ( $T, N$, and $\mathrm{M}$ components). All statistical analyses were performed twosided at a significance level of $P=0.05$, using the statistical package SPSS (SPSS Inc., Chicago, IL, USA).

\section{RESULTS}

After a mean follow-up of 43 months (95\% CI: 37-49 months; range: $2-191$ months), 64 (41\%) patients had died, the probability of survival being 69 and $54 \%$ at 2 and 5 years, respectively. A total of 50 patients died because of tumour progression and 14 due to other causes. In all, 55 (35\%) patients developed tumour recurrence, 33 of whom presented as locoregional relapse, 12 as distant metastases (eight in liver, three in lung, and one in bone), nine as peritoneal seeding, and one as stump. All but three patients with tumour recurrence died from it.

\section{Correlation between MVD, p53 expression, and VEGF expression}

The median microvessel count was 98.9. (95\% CI: $94.7-103.2)$, and this value was used to dichotomise the series. p53 expression was detected in $71(46 \%)$ patients (Table 2). p53 protein expression was significantly associated with MVD $\geqslant 100$ (OR: $2.22,95 \%$ CI: $1.26-3.88 ; P=0.005)$.

Vascular endothelial growth factor expression was detected in $116(74 \%)$ patients (Table 2). There was a significant association with MVD $\geqslant 100$ (OR: $2.65,95 \%$ CI: $1.33-5.29 ; P=0.005$ ). There was no association between p53 and VEGF expression.

\section{Correlation between MVD, p53 expression, and VEGF expression, and clinicopathological characteristics}

Neither p53 positivity nor VEGF expression was related to any of the clinicopathological parameters reported in Table 1. On the

Table 2 Distribution of tumour microvessel density, p53 expression, and VEGF expression in patients included in the study $(n=156)$

\begin{tabular}{ll}
\hline $\begin{array}{l}\text { Tumor microvessel density } \\
<100\end{array}$ & $74(47.4 \%)$ \\
$\geqslant 100$ & $82(52.6 \%)$ \\
& \\
p53 expression & $85(54.5 \%)$ \\
Negative & $71(45.5 \%)$ \\
Positive & \\
VEGF expression & \\
Negative & $40(25.6 \%)$ \\
Positive+ & $83(53.2 \%)$ \\
Positive++ & $33(21.2 \%)$ \\
\hline
\end{tabular}

VEGF = vascular endothelial growth factor. contrary, a statistically significant association was found between MVD $\geqslant 100$ and lymph node metastases $(P<0.003)$. As shown in Table 3, the lymph node ratio was also higher when MVD was elevated $(P<0.02)$, as well as the $\mathrm{pN}$ stage $(P<0.003)$.

\section{Tumour recurrence and disease-free survival}

There were statistically significant associations between tumour recurrence and tumour MVD $\geqslant 100$, p53 expression, and VEGF expression (Table 4). Other significant parameters found in the univariate analysis of tumour recurrence were pT stage $(P<0.0001)$, pN stage $(P<0.0001)$, pTNM stage $(P<0.0001)$, lymph node ratio $(P<0.0001)$, lymphatic invasion $(P<0.0001)$, Lauren classification $(P<0.005)$, signet-ring cell-type tumours $(P<0.013)$, degree of differentiation $(P<0.008)$, and extent of lymphadenectomy $(P<0.0001)$.

Both MVD $\geqslant 100(P=0.05)$ and VEGF expression $(P<0.02)$ were associated with a shorter disease-free survival in the univariate analysis (Table 4). Other significant parameters found in the analysis of disease-free survival were pT stage $(P<0.0001)$, pN stage $(P<0.0001)$, pTNM stage $(P<0.0001)$, lymph node ratio $(P<0.0001)$, lymphatic invasion $(P<0.0001)$, Lauren classification $(P<0.0039)$, signet-ring cell-type tumours $(P<0.01)$, degree of differentiation $(P<0.0048)$, and extent of lymphadenectomy $(P<0.0001)$. No correlation between MVD, p53 expression, and VEGF expression, and the type of recurrence (locoregional relapse $v s$ distant metastases) was found.

The multivariate analysis identified lymph node ratio $\geqslant 30 \%$, D1 lymphadenectomy, p53 expression, and VEGF expression as independent predictors of tumour recurrence and disease-free survival (Table 5).

\section{Overall survival}

In the univariate analysis, factors influencing overall survival were pTNM stage $(P<0.0001)$, pT $(P<0.0001)$, pN $(P<0.0001)$, lymph node ratio $(P<0.0001)$, signet-ring cell-type tumours $(P<0.01)$, degree of differentiation $(P<0.005)$, Lauren classification $(P<0.005)$, lymphatic invasion $(P<0.0001)$, perineural invasion $(P<0.39)$, and extent of lymphadenectomy $(P<0.0001)$. In addition, VEGF expression was associated with a shorter overall survival (HR: 2.48, 95\% CI: $1.16-5.28 ; P=0.01$ ) (Figure 4). By contrast, neither p53 expression (HR: 1.61, 95\% CI: 0.93-2.80; $P=0.08$ ) nor MVD $\geqslant 100$ (HR: $1.70,95 \%$ CI: $0.95-3.02 ; P=0.07$ ) reached statistical significance in this analysis.

The multivariate Cox's regression analysis revealed that pT3 stage or higher, lymph node ratio $\geqslant 30 \%$, D1 lymphadenectomy,

Table 3 Correlation between tumour microvessel density and lymph node metastases

\begin{tabular}{lccc}
\hline & \multicolumn{3}{c}{ Tumor microvessel density } \\
\cline { 2 - 4 } & $<\mathbf{l 0 0}(\mathbf{n}=\mathbf{7 4})$ & $\geqslant \mathbf{1 0 0}(\mathbf{n}=\mathbf{8 2})$ & P-value $^{\mathbf{a}}$ \\
\hline Lymph node ratio $^{\mathrm{b}}$ & & & \\
O\% $(n=66)$ & 40 & 26 & \\
$<30 \%(n=48)$ & 18 & 30 & $<0.02$ \\
$\geqslant 30 \%(n=42)$ & 16 & 26 & \\
pN stage & & & \\
No $(n=66)$ & 40 & 26 & \\
NI $(n=54)$ & 19 & 35 & $<0.003$ \\
N2 $(n=33)$ & 13 & 20 & \\
N3 $(n=3)$ & 2 & 1 & \\
\hline
\end{tabular}

${ }^{a} \chi^{2}$ test. ${ }^{b}$ Number of affected lymph nodes divided by the total number of lymph nodes. 'According to the 5 th edition of the tumour-node-metastasis classification of the International Union Against Cancer (UICC) ${ }^{18}$; $\mathrm{pN}=$ pathological lymph node. 
Table 4 Influence of tumour microvessel density, p53 expression, and VEGF expression on tumor recurrence and disease-free survival (univariate analysis)

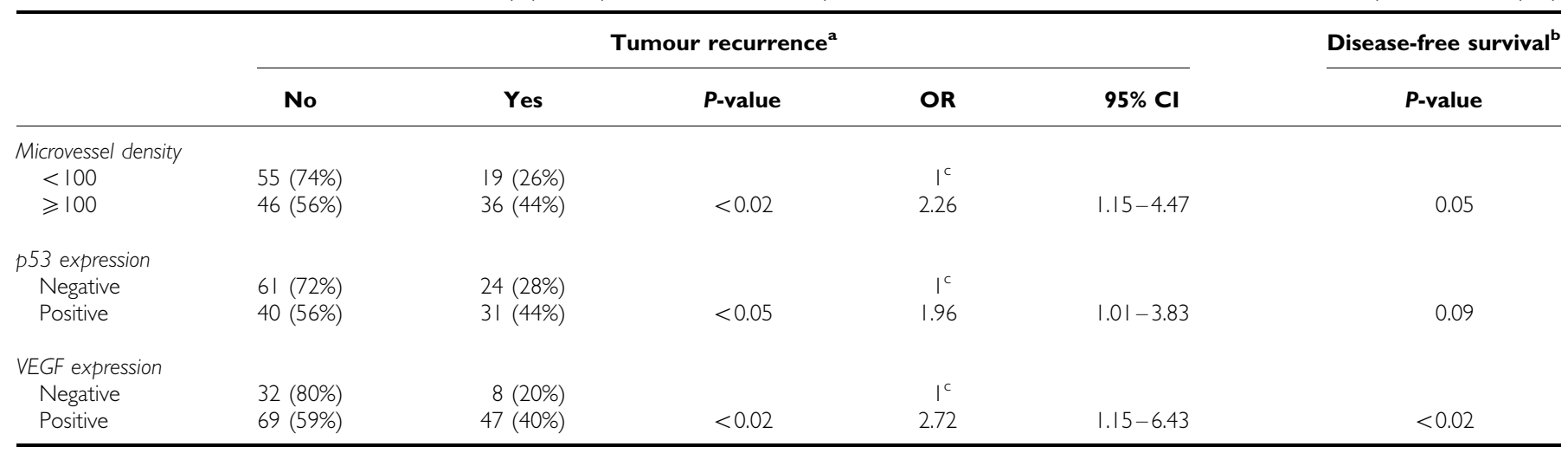

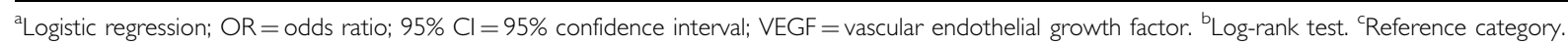

Table 5 Prognostic factors of tumour recurrence and disease-free survival (multivariate analysis)

\begin{tabular}{|c|c|c|c|c|c|c|}
\hline & \multicolumn{5}{|c|}{ Tumor recurrence $^{a}$} & \multirow{2}{*}{$\frac{\text { Disease-free survival }^{\text {b }}}{P \text {-value }}$} \\
\hline & No & Yes & $P$-value & OR & $95 \% \mathrm{Cl}$ & \\
\hline \multicolumn{7}{|c|}{ Lymphadenectomy } \\
\hline D2 & 80 (75\%) & $26(24 \%)$ & & $I^{c}$ & & \\
\hline $\mathrm{DI}$ & $21(42 \%)$ & $29(58 \%)$ & 0.0005 & 6.93 & $2.33-20.55$ & $<0.0001$ \\
\hline \multicolumn{7}{|c|}{ Lymph node ratio } \\
\hline$\geqslant 30 \%$ & $14(33 \%)$ & $28(67 \%)$ & $<0.001$ & 9.98 & $2.57-38.76$ & $<0.005$ \\
\hline \multicolumn{7}{|c|}{ p53 expression } \\
\hline Negative & 61 (72\%) & $24(28 \%)$ & & $1^{c}$ & & \\
\hline Positive & $40(56 \%)$ & $31(44 \%)$ & $<0.02$ & 3.36 & $1.29-8.74$ & $<0.0005$ \\
\hline \multicolumn{7}{|c|}{ VEGF expression } \\
\hline
\end{tabular}

aLogistic regression; OR = odds ratio; 95\% Cl=95\% confidence interval; VEGF = vascular endothelial growth factor. ${ }^{\mathrm{b}} \mathrm{Cox}$ 's regression. ${ }^{\mathrm{C}}$ Reference category

the presence of perineural invasion, p53 expression, and VEGF expression were independently associated with a shorter overall survival (Table 6).

\section{Influence of MVD, p53 expression, and VEGF expression on the clinical outcome of patients receiving chemotherapy}

The predictive value of MVD, p53 expression, and VEGF expression was also evaluated in the subset of 103 patients who received adjuvant chemotherapy. As shown in Table 7, patients whose tumours did not show p53 expression had a higher probability of overall survival than those whose tumours presented p53 expression $(P=0.01)$. By contrast, MVD and VEGF expression did not correlate with overall survival. Finally, neither MVD nor p53 and VEGF expression predicted survival in patients who did not receive chemotherapy $(n=53)$.

\section{DISCUSSION}

Surgical resection is the mainstay of treatment for gastric cancer. However, the prognosis after resection has remained unsatisfactory because of a high incidence of postoperative recurrence. The identification of variables in gastric tumour biology might lead to a more precise assessment of outcome and response to therapy. In the present study, we investigated the potential prognostic value of MVD, p53 expression, and VEGF expression.

p53 expression was detected in $46 \%$ of patients, which falls within the range $(40-60 \%)$ of previously published gastric cancer series (Joypaul et al, 1994; Gabbert et al, 1995; Victorzon et al, 1996). Use of the immunohistochemical detection of p53 as a prognostic marker has yielded conflicting results (Fenoglio-Preiser et al, 2003). These discrepancies may, in part, be due to the limitations of p53 immunodetection. In fact, p53 immunoreactivity correlates with the presence or absence of gene mutations examined by direct sequencing in $50 \%$ of advanced gastric cancers when exons 5-9 are examined (Tolbert et al, 1999). Technical issues can also contribute to divergent results. In order to overcome these limitations, we followed a meticulous methodology using monoclonal antibody BP53-12 that is similar to antibody DO7, antigen retrieval, and a standard counting method.

In some studies, the expression of p53 was associated with a higher frequency of serosal, vascular, and lymphatic invasion, increased lymph node metastases and, consequently, a more advanced tumour stage (Kakeji et al, 1993; Kim et al, 1997; Monig et al, 1997; Maehara et al, 1999). By contrast, other authors have not shown the association of p53 expression with node metastases or serosal invasion (Baba et al, 1998; Maeda et al, 1998). Our study agrees with these latter results, since p53 expression did not correlate to a more advanced tumour stage. In agreement with 


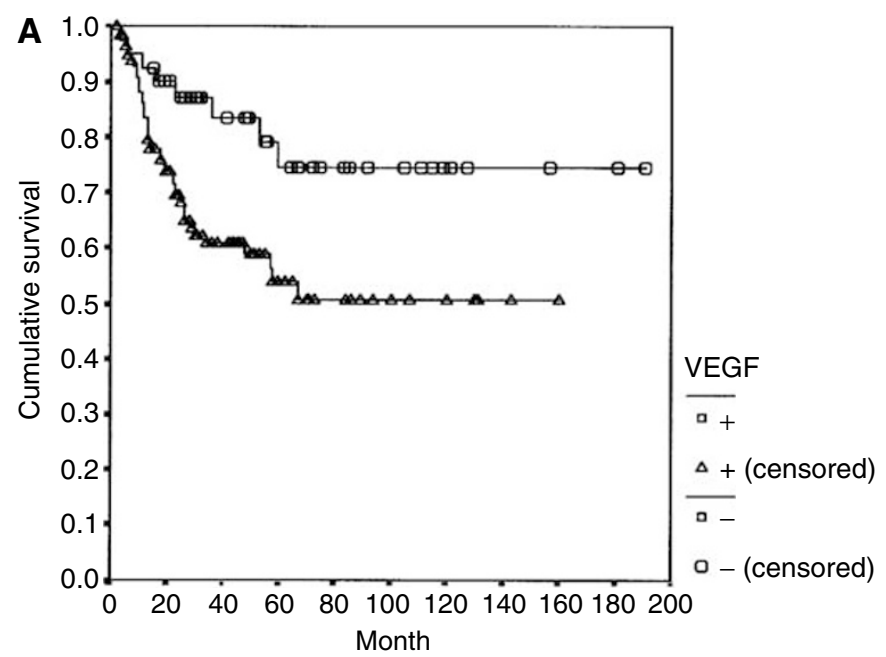

Table 6 Prognostic factors of overall survival (multivariate analysis) ${ }^{a}$

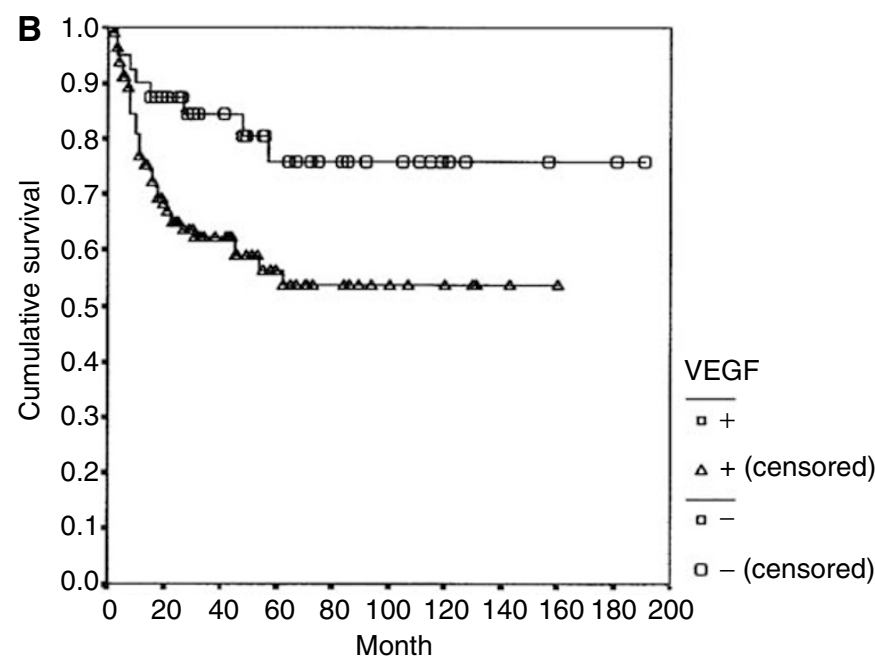

Figure 4 (A) Overall survival in patients with VEGF-negative and VEGFpositive tumours $(P<0.02)$. (B) Disease-free survival in patients with VEGF-negative and VEGF-positive tumours $(P<0.02)$.

these results, p53 mutations have been found in $37 \%$ of patients with early gastric cancer (Uchino et al, 1993), and p53 expression has even been detected in metaplastic gastric mucosa (Ochiai et al, 1996). Thus, p53 inactivation may occur at an early stage of gastric carcinogenesis, which explains our finding that p53 expression indicated a poor prognosis independent of the lymph node ratio or the depth of invasion (pT). Finally, the worse prognosis of patients whose tumours expressed p53 may actually reflect a higher tendency to recur. In our study, the recurrence rate in $\mathrm{p} 53$ negative patients was $28 \%$ compared to $44 \%$ in p53 positive patients $(P<0.05)$. Similar findings have been reported in Japanese series (Maeda et al, 1996; Maehara et al, 1999).

The prognostic role of tumour angiogenesis was also investigated following a methodology accepted internationally (Vermeulen et al, 1996). We used a monoclonal antibody against adhesion molecule CD34 to stain the vascular endothelium, which was found to be superior to other markers (Tanigawa et al, 1996; Tanigawa et al, 1998). Our study confirm's the results of (Maeda et al, 1995) and (Xiangming et al, 1998) showing that MVD correlates with lymph node metastases in gastric cancer, as in esophageal cancer (Igarashi et al, 1998). MVD was also associated with a higher recurrence rate and a shorter disease-free survival in the univariate analysis. However, this association was not statistically significant in the multivariate regression analysis probably due to the positive

\begin{tabular}{|c|c|c|c|c|c|}
\hline & Dead & Alive & HR & $95 \% \mathrm{Cl}$ & $P$-value \\
\hline \multicolumn{6}{|l|}{ pT stage ${ }^{b}$} \\
\hline $\mathrm{TI}$ & $4(14 \%)$ & $24(86 \%)$ & $1^{c}$ & & \\
\hline $\mathrm{T} 2$ & $16(21 \%)$ & $59(79 \%)$ & 1.18 & $0.37-3.78$ & 0.77 \\
\hline T3 & $31(58 \%)$ & $22(42 \%)$ & 3.74 & $1.16-12.02$ & $<0.03$ \\
\hline \multicolumn{6}{|c|}{ Lymph node ratio $^{d}$} \\
\hline 0 & $10(15 \%)$ & $56(85 \%)$ & $1^{c}$ & & \\
\hline$<30 \%$ & $14(29 \%)$ & $34(7 \mid \%)$ & 2.95 & $1.14-7.66$ & $<0.03$ \\
\hline$\geqslant 30 \%$ & $27(64 \%)$ & $15(36 \%)$ & 7.75 & $3.25-18.47$ & $<0.0001$ \\
\hline \multicolumn{6}{|c|}{ Lymphadenectomy } \\
\hline D2 & $24(23 \%)$ & $82(77 \%)$ & $1^{c}$ & & \\
\hline DI & $27(54 \%)$ & $23(46 \%)$ & 4.40 & $2.30-8.44$ & $<0.0001$ \\
\hline \multicolumn{6}{|c|}{ Perineural invasion } \\
\hline Absence & $44(32 \%)$ & $92(68 \%)$ & $1^{c}$ & & \\
\hline Presence & $7(35 \%)$ & $13(65 \%)$ & 2.83 & $1.17-6.85$ & $<0.03$ \\
\hline \multicolumn{6}{|c|}{ p53 expression } \\
\hline Negative & $23(27 \%)$ & $62(73 \%)$ & $1^{c}$ & & \\
\hline Positive & $28(39 \%)$ & $43(60 \%)$ & 2.30 & $1.21-4.36$ & $<0.02$ \\
\hline \multicolumn{6}{|c|}{ VEGF expression } \\
\hline Negative & $8(20 \%)$ & $32(80 \%)$ & $1^{c}$ & & \\
\hline Positive & $43(37 \%)$ & $73(63 \%)$ & 2.99 & $1.34-6.67$ & $<0.01$ \\
\hline
\end{tabular}

${ }^{a}$ Cox's regression; $\mathrm{HR}=$ hazard ratio; $95 \% \mathrm{Cl}=95 \%$ confidence interval; VEGF = vas vascular endothelial growth factor; $\mathrm{pT}=$ pathological tumour. ${ }^{\mathrm{b}}$ According to the 5 th edition of the tumor-node metastasis classification of the International Union Against Cancer (UICC) ${ }^{18}$. ${ }^{C}$ Reference category. ${ }^{d}$ Number of affected lymph nodes divided by the total number of lymph nodes.

Table 7 Influence of tumour microvessel density, p53 expression, and VEGF expression on overall survival following adjuvant chemotherapy

\begin{tabular}{|c|c|c|c|c|c|c|}
\hline & \multicolumn{3}{|c|}{$\begin{array}{l}\text { Patients receiving } \\
\text { chemotherapy } \\
(n=103)\end{array}$} & \multicolumn{3}{|c|}{$\begin{array}{l}\text { Patients not receiving } \\
\text { chemotherapy } \\
(n=53)\end{array}$} \\
\hline & $n$ & $\begin{array}{c}\text { Survival } \\
\left(^{(\%)^{\mathbf{a}}}\right.\end{array}$ & P-value & $n$ & $\begin{array}{c}\text { Survival } \\
\text { (\%) }^{\mathbf{a}}\end{array}$ & P-value \\
\hline \multicolumn{7}{|c|}{ Microvessel density } \\
\hline$<100$ & 45 & 76 & 0.58 & 29 & 31 & \\
\hline$\geqslant 100$ & 58 & 71 & & 24 & 33 & 0.86 \\
\hline \multicolumn{7}{|c|}{ p53 expression } \\
\hline Negative & 58 & 83 & 0.01 & 27 & 30 & 0.69 \\
\hline Positive & 45 & 60 & & 26 & 35 & \\
\hline \multicolumn{7}{|c|}{ VEGF expression } \\
\hline Negative & 33 & 82 & 0.16 & 7 & 43 & 0.52 \\
\hline Positive & 70 & 69 & & 46 & 30 & \\
\hline
\end{tabular}

${ }^{a}$ Overall survival at 2 years, logistic regression. VEGF = vascular endothelial growth factor.

correlation between MVD and both p53 expression and VEGF expression. The predictive value of MVD has also been suggested in other studies in which a higher MVD was associated with the development of distant metastases (Tanigawa et al, 1996) or bone marrow micrometastases (Maehara et al, 1998). Similarly, experimental studies using antiangiogenic agents, such as TNP-470, have shown effectiveness in decreasing tumour proliferative activity and inhibiting the development of liver and peritoneal metastases (Kanai et al, 1997; Yoshikawa et al, 2000). These findings reinforce the relationship between tumour angiogenesis and the spread of metastases. 
Tumour angiogenesis is a complex, highly regulated process depending on the balance between activator and inhibitor factors (Castells and Rustgi, 2003). Vascular endothelial growth factor is a powerful and specific inducer of new vasculature in several neoplasms. In our study, MVD correlated with VEGF expression in tumour cells, in accordance with Maeda et al (1996). We used a standardised method to detect VEGF expression. Our patients were classified into two categories, by the presence or absence of staining reaction. We decided to consider cases as positives or negatives independent of the intensity of the staining. This fact can justify the relatively low proportion of patients whose tumours were considered negative for VEGF $(25.6 \%)$ in the present study, which is similar to that recently reported in other series (Song et al, 2002; Joo et al, 2003).

Vascular endothelial growth factor induces the formation of new immature vessels, with basal membrane holes, favouring the progression of tumour cells into the vascular space. VEGF expression in gastric cancer has been associated with various clinicopathological parameters such as degree of differentiation (Tanigawa et al, 1997), intestinal-type tumours (Takahashi et al, 1996), lymphatic invasion, and vascular invasion (Maeda et al, 1996). Maehara et al (2000a) demonstrated that VEGF expression was an independent risk factor for vascular invasion that might account for a large number of metastases. This correlation was not observed in our series, but it should be taken into account that it corresponded to curatively resected patients who had a lower probability of metastatic dissemination. However, although VEGF expression was not associated with any tumour-related characteristic in our study, similar as in the series of Baba et al (1998), this parameter had an independent predictive value with respect to tumour recurrence, disease-free survival, and overall survival. These results suggest that VEGF expression might be a useful and powerful prognostic marker in patients with gastric cancer operated on for cure.

In the multivariate analysis, p53 expression and VEGF expression were independent prognostic factors. Similarly, concurrence of p53 expression and VEGF expression occurred in only $38 \%$ of patients, and there was no correlation between both markers. Our results indicate that p53 and VEGF expression are important factors to upregulate tumour angiogenesis. Whereas the role of VEGF as an inductor of angiogenesis is well known, the mechanism of p53 to do so is not as well established. A few experimental studies have been published linking p53 and angiogenesis. Kieser et al (1994) demonstrated that mutant p53 potentiates protein kinase $\mathrm{C}$ induction of VEGF, then promoting the development of new vasculature. Supporting these findings, Mukhopadhyay et al (1995) showed that wild-type p53 downregulated endogenous VEGF mRNA level, as well as VEGF promoter activity, whereas mutant forms of p53 had no effect. The authors suggested that wild-type p53 may play a role in suppressing angiogenesis. These experimental results contrast with those observed in clinical series. In fact, our results suggest that p53 and VEGF regulate tumour angiogenesis in patients with gastric cancer, but they do not support the fact that p53 stimulates the appearance of new vasculature by enhancing the expression of VEGF. Reviewing the literature, we found three clinical studies with similar findings as ours, confirming that the expression of p53 does not correlate with VEGF expression in gastric cancer patients (Baba et al, 1998; Giatromanolaki et al, 2000; Joo et al, 2002).

Preliminary studies suggested that the determination of p53 status and angiogenesis may be useful to predict response to chemotherapy. Indeed, p53 gene inactivation by either mutation or deletion often results in resistance to antineoplastic drugs. In these in vitro studies, gastric and esophageal cancer cells with p53 expression were resistant to 5-fluorouracil, mitomycin-C, and cisplatin (Lowe et al, 1994; Nabeya et al, 1995). Two clinical studies have evaluated the influence of p53 status in patients with locally advanced gastric cancer receiving neoadjuvant treatment. In one of them, patients with negative p53 expression had a greater tumour response to chemotherapy using 5-fluorouracil (72 vs 12\%, $P<0.004)$ (Cascinu et al, 1998). Similarly, the second study found that p53-negative and VEGF-positive patients responded better to chemotherapy with 5-fluorouracil and cisplatin (Boku et al, 1998). Finally, Diez et al (2000) reported in a series of 46 patients with gastric cancer receiving adjuvant chemotherapy that the absence of p53 overexpression was associated with longer survival. In agreement with these observations, we demonstrated that chemotherapy was less effective in patients whose tumours showed p53 expression, whereas MVD and VEGF expression did not have any predictive value in these settings. To our knowledge, this is the largest series assessing the relationship of p53 alteration to clinical outcome following adjuvant chemotherapy in gastric cancer, and its results may have noteworthy clinical implications.

In conclusion, this study shows that the expression of p53, VEGF, and a higher MVD are associated with tumour recurrence in gastric cancer patients resected with curative intent. The expression of p53 protein and VEGF are independent prognostic factors of disease-free and overall survival in gastric cancer patients having resection with curative intent. When tumour cells express p53 protein, the therapeutic efficacy of adjuvant chemotherapy is lost. Further studies are required to evaluate the potential clinical applications in the management of patients with gastric cancer.

\section{ACKNOWLEDGEMENTS}

This work was supported in part by grants from "La Caixa" (02/126-00) and the Instituto de Salud Carlos III (C03/02 and $\mathrm{C} 03 / 10)$.

\section{REFERENCES}

Averbach AM, Jacquet P (1996) Strategies to decrease the incidence of intra-abdominal recurrence in resectable gastric cancer. Br J Surg 83: $726-733$

Baba M, Konno H, Maruo Y, Tanaka T, Kanai T, Matsumoto K, Matsuura M, Nishino N, Maruyama K, Nakamura S, Baba S (1998) Relationship of p53 and vascular endothelial growth factor expression of clinicopathological factors in human scirrhous gastric cancer. Eur Surg Res 30: $130-137$

Boku N, Chin K, Hosokawa K, Ohtsu A, Tajiri H, Yoshida S, Yamao T, Kondo H, Shirao K, Shimada Y, Saito D, Hasebe T, Mukai K, Seki S, Saito H, Johnston PG (1998) Biological markers as a predictor for response and prognosis of unresectable gastric cancer patients treated with 5-fluorouracil and cis-platinum. Clin Cancer Res 4: 1469-1474

Cascinu S, Graziano F, Del Ferro E, Staccioli MP, Ligi M, Carnevali A, Muretto P, Catalano G (1998) Expression of p53 protein and resistance to

preoperative chemotherapy in locally advanced gastric carcinoma. Cancer 83: 1917 - 1922

Castells A, Rustgi AK (2003) Tumour growth, invasion and metastasis. In Gastrointestinal Cancers, Rustgi AK, Crawford JM (eds) pp 69-80. Philadelphia: Saunders

Chin KV, Ueda K, Pastan I, Gottesman MM (1992) Modulation of activity of the promoter of the human MDR1 gene by Ras and p53. Science 255: $459-462$

Diez M, Medrano MJ, Gutierrez A, Lopez A, Muguerza JM, Hernandez P, Lozano O, Noguerales F, Ruiz A, Granell J (2000) P53 protein expression in gastric adenocarcinoma. Negative predictor of survival after postoperative adjuvant chemotherapy. Anticancer Res 20: 3929-3933

Earle CC, Maroun JA (1999) Adjuvant chemotherapy after curative resection for gastric cancer in non-Asian patients: revisiting a metaanalysis of randomised trials. Eur J Cancer 35: 1059-1064 
Fenoglio-Preiser CM, Wang J, Stemmermann GN, Noffsinger A (2003) TP53 and gastric carcinoma: a review. Hum Mutat 21: 258-270

Gabbert HE, Muller W, Schneiders A, Meier S, Hommel G (1995) The relationship of $\mathrm{p} 53$ expression to the prognosis of 418 patients with gastric carcinoma. Cancer 76: 720-726

Giatromanolaki A, Koukourakis MI, Stathopoulos GP, Kapsoritakis A, Paspatis G, Kakolyris S, Sivridis E, Georgoulias V, Harris AL, Gatter KC (2000) Angiogenic interactions of vascular endothelial growth factor, of thymidine phosphorylase, and of 553 protein expression in locally advanced gastric cancer. Oncol Res 12: 33-41

Grau JJ, Estape J, Fuster J, Filella X, Visa J, Teres J, Soler G, Albiol S, GarciaValdecasas JC, Grande L, Bombi J, Bordas J, Alcobendas F (1998) Randomized trial of adjuvant chemotherapy with mitomycin plus ftorafur versus mitomycin alone in resected locally advanced gastric cancer. J Clin Oncol 16: 1036-1039

Greenlee RT, Hill-Harmon MB, Murray T, Thun M (2001) Cancer statistics, 2001. CA Cancer J Clin 51: 15-36

Harris AL (1997) Antiangiogenesis for cancer therapy. Lancet 349(Suppl 2): SII13 - SII15

Hermans J, Bonenkamp JJ, Boon MC, Bunt AM, Ohyama S, Sasako M, van de Velde CJ (1993) Adjuvant therapy after curative resection for gastric cancer: meta-analysis of randomized trials. J Clin Oncol 11: $1441-1447$

Hundahl SA, Phillips JL, Menck HR (2000) The National Cancer Data Base Report on poor survival of US gastric carcinoma patients treated with gastrectomy: Fifth Edition American Joint Committee on Cancer staging, proximal disease, and the different disease hypothesis. Cancer 88: 921 - 932

Igarashi M, Dhar DK, Kubota H, Yamamoto A, El Assal O, Nagasue N (1998) The prognostic significance of microvessel density and thymidine phosphorylase expression in squamous cell carcinoma of the esophagus. Cancer 82: $1225-1232$

Inoue K, Ozeki Y, Suganuma T, Sugiura Y, Tanaka S (1997) Vascular endothelial growth factor expression in primary esophageal squamous cell carcinoma. Association with angiogenesis and tumour progression. Cancer 79: 206-213

Joo YE, Sohn YH, Joo SY, Lee WS, Min SW, Park CH, Rew JS, Choi SK, Park CS, Kim YJ, Kim SJ (2002) The role of vascular endothelial growth factor (VEGF) and p53 status for angiogenesis in gastric cancer. Korean J Intern Med 17: 211-219

Joo YE, Rew JS, Seo YH, Choi SK, Kim YJ, Park CS, Kim SJ (2003) Cyclooxygenase-2 overexpression correlates with vascular endothelial growth factor expression and tumour angiogenesis in gastric cancer. J Clin Gastroenterol 37: $28-33$

Joypaul BV, Hopwood D, Newman EL, Qureshi S, Grant A, Ogston SA, Lane DP, Cuschieri A (1994) The prognostic significance of the accumulation of p53 tumour-suppressor gene protein in gastric adenocarcinoma. Br J Cancer 69: $943-946$

Kakeji Y, Korenaga D, Tsujitani S, Baba H, Anai H, Maehara Y, Sugimachi K (1993) Gastric cancer with p53 overexpression has high potential for metastasising to lymph nodes. Br J Cancer 67: 589-593

Kanai T, Konno H, Tanaka T, Matsumoto K, Baba M, Nakamura S, Baba S (1997) Effect of angiogenesis inhibitor TNP-470 on the progression of human gastric cancer xenotransplanted into nude mice. Int J Cancer 71: $838-841$

Kieser A, Weich HA, Brandner G, Marme D, Kolch W (1994) Mutant p53 potentiates protein kinase $\mathrm{C}$ induction of vascular endothelial growth factor expression. Oncogene 9: 963-969

Kim JH, Uhm HD, Gong SJ, Shin DH, Choi JH, Lee HR, Noh SH, Kim BS, Cho JY, Rha SY, Yoo NC, Chung HC, Roh JK, Min JS, Lee KS, Kim BS (1997) Relationship between p53 overexpression and gastric cancer progression. Oncology 54: 166-170

Lacueva FJ, Calpena R (2001) Gastric cancer recurrence: clues for future approaches to avoiding an old problem. J Clin Gastroenterol 32: 3-4

Lowe SW, Bodis S, McClatchey A, Remington L, Ruley HE, Fisher DE, Housman DE, Jacks T (1994) p53 status and the efficacy of cancer therapy in vivo. Science 266: 807-810

Lowe SW, Ruley HE, Jacks T, Housman DE (1993) p53-dependent apoptosis modulates the cytotoxicity of anticancer agents. Cell 74: 957-967

Maeda K, Chung YS, Ogawa Y, Takatsuka S, Kang SM, Ogawa M, Sawada T, Sowa M (1996) Prognostic value of vascular endothelial growth factor expression in gastric carcinoma. Cancer 77: 858-863

Maeda K, Chung YS, Takatsuka S, Ogawa Y, Sawada T, Yamashita Y, Onoda N, Kato Y, Nitta A, Arimoto Y (1995) Tumour angiogenesis as a predictor of recurrence in gastric carcinoma. J Clin Oncol 13: 477-481
Maeda K, Kang SM, Onoda N, Ogawa M, Sawada T, Nakata B, Kato Y, Chung YS, Sowa M (1998) Expression of p53 and vascular endothelial growth factor associated with tumour angiogenesis and prognosis in gastric cancer. Oncology 55: 594-599

Maehara Y, Hasuda S, Abe T, Oki E, Kakeji Y, Ohno S, Sugimachi K (1998) Tumour angiogenesis and micrometastasis in bone marrow of patients with early gastric cancer. Clin Cancer Res 4: 2129-2134

Maehara Y, Kabashima A, Koga T, Tokunaga E, Takeuchi H, Kakeji Y, Sugimachi K (2000a) Vascular invasion and potential for tumour angiogenesis and metastasis in gastric carcinoma. Surgery 128: $408-416$

Maehara Y, Oki E, Abe T, Tokunaga E, Shibahara K, Kakeji Y, Sugimachi K (2000b) Overexpression of the heat shock protein HSP70 family and p53 protein and prognosis for patients with gastric cancer. Oncology 58: $144-151$

Maehara Y, Tomoda M, Hasuda S, Kabashima A, Tokunaga E, Kakeji Y, Sugimachi K (1999) Prognostic value of p53 protein expression for patients with gastric cancer - a multivariate analysis. $\mathrm{Br} J$ Cancer 79: $1255-1261$

Monig SP, Eidt S, Zirbes TK, Stippel D, Baldus SE, Pichlmaier H (1997) p53 expression in gastric cancer: clinicopathological correlation and prognostic significance. Dig Dis Sci 42: 2463-2467

Mukhopadhyay D, Tsiokas L, Sukhatme VP (1995) Wild-type p53 and v-Src exert opposing influences on human vascular endothelial growth factor gene expression. Cancer Res 55: 6161-6165

Nabeya Y, Loganzo F, Jr, Maslak P, Lai L, de Oliveira AR, Schwartz GK, Blundell ML, Altorki NK, Kelsen DP, Albino AP (1995) The mutational status of p53 protein in gastric and esophageal adenocarcinoma cell lines predicts sensitivity to chemotherapeutic agents. Int J Cancer 64: $37-46$

Ochiai A, Yamauchi Y, Hirohashi S (1996) p53 mutations in the nonneoplastic mucosa of the human stomach showing intestinal metaplasia. Int J Cancer 69: 28-33

Parkin DM, Pisani P, Ferlay J (1999) Estimates of the worldwide incidence of 25 major cancers in 1990. Int J Cancer 80: 827-841

Sobin LH, Fleming ID (1997) TNM Classification of Malignant tumours, fifth edition (1997). Union Internationale Contre le Cancer and the American Joint Committee on Cancer. Cancer 80: $1803-1804$

Song ZJ, Gong P, Wu YE (2002) Relationship between the expression of iNOS, VEGF, tumour angiogenesis and gastric cancer. World $J$ Gastroenterol 8: $591-595$

Takahashi Y, Cleary KR, Mai M, Kitadai Y, Bucana CD, Ellis LM (1996) Significance of vessel count and vascular endothelial growth factor and its receptor (KDR) in intestinal-type gastric cancer. Clin Cancer Res 2: $1679-1684$

Tanigawa N, Amaya H, Matsumura M, Lu C, Iki M (1998) Association between tumour angiogenesis and Borrmann type 4 carcinomas of the stomach. Oncology 55: 461-467

Tanigawa N, Amaya H, Matsumura M, Shimomatsuya T (1997) Correlation between expression of vascular endothelial growth factor and tumour vascularity, and patient outcome in human gastric carcinoma. J Clin Oncol 15: 826-832

Tanigawa N, Amaya H, Matsumura M, Shimomatsuya T, Horiuchi T, Muraoka R, Iki M (1996) Extent of tumour vascularization correlates with prognosis and hematogenous metastasis in gastric carcinomas. Cancer Res 56: 2671-2676

Tolbert DM, Noffsinger AE, Miller MA, DeVoe GW, Stemmermann GN, Macdonald JS, Fenoglio-Preiser CM (1999) p53 immunoreactivity and single-strand conformational polymorphism analysis often fail to predict p53 mutational status. Mod Pathol 12: 54-60

Uchino S, Noguchi M, Ochiai A, Saito T, Kobayashi M, Hirohashi S (1993) p53 mutation in gastric cancer: a genetic model for carcinogenesis is common to gastric and colorectal cancer. Int J Cancer 54: $759-764$

Vermeulen PB, Gasparini G, Fox SB, Toi M, Martin L, McCulloch P, Pezzella F, Viale G, Weidner N, Harris AL, Dirix LY (1996) Quantification of angiogenesis in solid human tumours: an international consensus on the methodology and criteria of evaluation. Eur J Cancer 32A: $2474-2484$

Victorzon M, Nordling S, Haglund C, Lundin J, Roberts PJ (1996) Expression of p53 protein as a prognostic factor in patients with gastric cancer. Eur J Cancer 32A: 215-220

Witte L, Hicklin DJ, Zhu Z, Pytowski B, Kotanides H, Rockwell P, Bohlen P (1998) Monoclonal antibodies targeting the VEGF receptor-2 
(Flk1/KDR) as an anti-angiogenic therapeutic strategy. Cancer Metastasis Rev 17: $155-161$

Xiangming C, Hokita S, Natsugoe S, Tanabe G, Baba M, Takao S, Kuroshima K, Aikou T (1998) Angiogenesis as an unfavorable factor related to lymph node metastasis in early gastric cancer. Ann Surg Oncol 5: $585-589$
Yoo CH, Noh SH, Shin DW, Choi SH, Min JS (2000) Recurrence following curative resection for gastric carcinoma. Br J Surg 87: 236-242

Yoshikawa T, Yanoma S, Tsuburaya A, Kobayashi O, Sairenji M, Motohashi H, Noguchi Y (2000) Angiogenesis inhibitor, TNP-470, suppresses growth of peritoneal disseminating foci. Hepatogastroenterology 47: $298-302$ 